\title{
SISTEM INFORMASI PENGENDALIAN INTERNAL PROSEDUR PENCATATAN AKUNTANSI PENGGAJIAN PADA PT. HALMAHERA KARYA TIMUR PERSADA MENGGUNAKAN VISUAL STUDIO
}

\section{INFORMATION SYSTEM FOR INTERNAL PROCEDURE CONTROL OF PAYMENT ACCOUNTING LISTING IN PT. HALMAHERA KARYA TIMUR PERSADA USE VISUAL STUDIO}

\author{
Darman Umagapi ${ }^{1}$, Syahril Hasan ${ }^{2}$ \\ ${ }^{1}$ Prodi Manajemen Informatika, ${ }^{2}$ Prodi Komputerisasi Akuntansi \\ Politeknik Sains dan Teknologi Wiratama Maluku Utara \\ Umagapie01@yahoo.com
}

\begin{abstract}
Abstrak
Perusahaan dituntut untuk lebih efisien, efektif, dan ekonomis dalam menentukan besarnya biaya operasional perusahaan, Gaji adalah sebuah bentuk pembayaran atau sebuah hak yang diberikan oleh perusahaan atau instansi kepada pegawai sesuai dengan Pasal 1 angka 30 Undang-Undang No. 13 Tahun 2003 tentang Ketenagakerjaan (UU Ketenagakerjaan). Oleh karena itu, tujuan penelitian adalah Agar mempermudah pihak perusahan dalam memberikan gaji atau upah kerja berdasarkan prosedur pencatatan penggajian dalam pendistribusian penerimaan gaji karyawan dengan mnggunakan aplikasi Visual Studio. Metode penelitian yang digunakan adalah metode deskriptif analitis dengan pendekatan studi kasus yang bertujuan untuk memberikan gambaran yang jelas mengenai data sehingga menghasilkan informasi yang berguna untuk menganalisis masalah pembayaran gaji pada PT. Halmahera Karya Timur Persada. Dari hasil penelitian dan pembahasan yang dilakukan adalah tahap perencanaan, desain, pengembangan sistem pada PT. Halmahera Karya Timur Persada, penulis dapat menyimpulkan bahwa sistem informasi akuntansi penggajian dan pencarian data pegawai lebih cepat, tepat dan mudah berperan dalam menunjang efektivitas pengendalian internal gaji pada perusahan.
\end{abstract}

\section{Kata Kunci: Sistem Informasi, Pengendalian Prosedur Internal, Visual Studio}

\begin{abstract}
Companies are required to be more efficient, effective, and economical in determining the amount of the company's operational costs. A salary is a form of payment or a right granted by the company or agency to employees in accordance with Article 1 number 30 of Law No. 13 of 2003 about employment (employment UU). Therefore, the purpose of the research is to make it easier for the company to provide salary or wages based on the payroll recording procedure in distributing employee salary receipts by using Visual Studio application. The research method used is descriptive analytical method with a case study approach that aims to provide an overview what is clear about the data so as to produce information that is useful to analyze the problem of salary payments at PT. Halmahera Karya Timur Persada. From the results of the research and discussion carried out is the stage of planning, design, development of the system at PT. Halmahera Karya Timur Persada, the
\end{abstract}


writer can conclude that payroll accounting information system and employee data search are faster, more accurate and easy to play a role in supporting the effectiveness of internal control of salary in the company.

\section{Keywords: Information Systems, Internal Procedure Control, Visual Studio}

\section{PENDAHULUAN}

Perkembangan teknologi sudah berkembang dengan pesat. Teknologi bukan lagi hanya sebagai media komunikasi untuk memudahkan pada wilayah pekerjaan. Teknologi juga telah merevolusi hidup kita,dari cara kita berkomunikasi, cara bekerja, berbisnis dan lain sebagainya. Zaman teknologi seperti saat ini memberi ruang lingkup yang sangat besar untuk mengorganisasikan segala kegiatan melalui cara baru, instan, transparan, akurat, inovatif, efektif serta efisien. Dengan adanya komputer maka data dapat diolah ke dalam berbagai bentuk informasi sesuai dengan keperluan masingmasing unit kerja.

Perusahaan dituntut untuk lebih efisien, efektif, dan ekonomis dalam menentukan besarnya biaya operasional perusahaan, karena faktor ini adalah salah satu yang terpenting untuk menghadapi persaingan yang semakin ketat dengan perusahaan lain. Dalam melaksanakan kegiatan operasi perusahaan diperlukan adanya manajemen perusahaan yang baik dengan ditunjang oleh personil yang berkualitas agar dapat berkarya secara efisien.

Gaji adalah sebuah bentuk pembayaran atau sebuah hak yang diberikan oleh sebuah perusahaan atau instansi kepada pegawai (Mardi: 2011). Untuk menjalankan kegiatannya dengan efektif dan efisien, sebuah perusahaan memerlukan suatu sistem pengolahan data informasi yang mendukungnya kebutuhan ini akan terpenuhi dengan adanya sistem informasi akuntansi. Sistem informasi akuntansi harus dirancang dan digunakan secara efektif karena informasi akuntansi merupakan bagian yang paling penting dari seluruh informasi yang diperlukan oleh manajemen.

PT. Halmahera Karya Timur Persada (PT. HKTP) merupakan salah satu perusahaan daerah yang bergerak dibidang jasa. Dimana pada sektor ini, gaji dan upah merupakan biaya yang paling dominan sehingga harus dikelola dengan baik. Sementara peneliti menemukan sering terjadinya keterlambatan penerimaan gaji / upah yang diterima oleh karyawan pada PT. Halmahera Karya Timur Persada.

Oleh karena itu, peneliti melihat perlunya perhatian terhadap sistem pengendalian internal atas prosedur akuntansi penggajian yang baik yaitu pendistribusian gaji yang tepat waktu dan sesuai dengan Pasal 1 angka 30 UndangUndang No. 13 Tahun 2003 tentang Ketenagakerjaan ("UU Ketenagakerjaan") sebagai berikut: "Upah adalah hak pekerja/buruh yang diterima dan dinyatakan dalam bentuk uang sebagai imbalan dari pengusaha atau pemberi kerja kepada pekerja/buruh yang ditetapkan dan dibayarkan menurut suatu perjanjian kerja, kesepakatan, atau peraturan perundangundangan, termasuk tunjangan bagi pekerja/buruh dan keluarganya atas suatu pekerjaan dan/atau jasa yang telah atau akan dilakukan".

\section{RUMUSAN MASALAH}

Berdasarkan uraian latar belakang sebelumnya maka dirumuskan masalah yaitu "Bagaimana Perancangan Sistem 
Informasi Pengendalian Internal Prosedur Pencatatan Akuntansi Penggajian pada PT. Halmahera Karya Timur Persada", tujuan penelitian adalah Merancang Sistem Informasi Pengedalian Internal Prosedur Pencatatan Akuntansi Penggajian pada PT. Halmahera Karya Timur Persada Agar mempermudah pihak perusahan dalam memberikan gaji atau upah kerja berdasarkan prosedur pencatatan penggajian dalam pendistribusian penerimaan gaji karyawan dengan mnggunakan Aplikasi Visual Studio.

\section{Tinjauan Pustaka}

\section{Defenisi Sistem Informasi}

Menurut Hall (2013:10), informasi sering diartikan sebagai data yang diolah dimana informasi tersebut ditentukan oleh efeknya terhadap pengguna, bukan dari efek bentuk fisiknya.

Menurut Tata Sutabri (2012:47) Sistem informasi terdiri dari komponenkomponen yang disebut blok bangunan (building block), yang terdiri dari blok masukan, blok model, blok keluaran, blok teknologi, blok basis data dan blok kendal

Menurut Sutarman (2012:13), "sistem informasi adalah sistem dapat didefinisikan dengan mengumpulkan, memproses, menyimpan, menganalisis, menyebarkan informasi untuk tujuan tertentu. Seperti sistem lainnya, sebuah sistem informasi terdiri atas input (data, instruksi) dan output (laporan, kalkulasi).

\section{Pengertian Pengendalian Internal}

"Pengendalian intern itu meliputi struktur organisasi dan semua cara-cara serta alat-alat yang dikoorninasikan dalam perusahaan dengan tujuan untuk memperoleh tujuan untuk menjaga keamanan harta milik perusahaan, memeriksa ketelitian dan kebenaran data akuntansi, mengajukan kebijakan manajemen yang telah diterapkan" (Suparjono 2011: 29).

\section{Pengertian Gaji}

Mardi (2011:107) mengemukakan bahwa: "Gaji adalah sebuah bentuk pembayaran atau sebuah hak yang diberikan oleh sebuah perusahaan atau instansi kepada pegawai”.

\section{Pengertian Sistem Akuntansi Penggajian}

Mardi (2011:107) menyatakan "Sistem akuntansi gaji dan upah adalah salah satu aplikasi pada sistem informasi akuntansi yang terus mengalami proses dalam bentuk batch (bertahap), disebut proses secara bertahap karena daftar gaji dibayarkan atau dibuat secara periodik (tiap mingguan, dua mingguan, atau bulanan) demikian pula pembayaran gaji sebagian besar pegawai dibayar pada waktu bersamaan".

\section{Pengertian Data}

Menurut Sutarman (2013:22), Data adalah fakta dari sesuatu pernyataan yang berasal dari kenyataan, dimana pernyataan tersebut merupakan hasil pengukuran atau pengamatan.

\section{Pengertian Basis Data (Database)}

Menurut Ladjmudin (2013:21), "Database merupakan kumpulan file yang saling terintegrasi, namun database tidak akan dapat diakses oleh siapapun tanpa adanya software aplikasi”. Menurut Ladjmudin (2013:129), "Database adalah sekumpulan data store (bisa dalam jumlah yang sangat besar) yang tersimpan dalam magnetic disk, optical disk, magnetic drum atau media penyimpanan sekunder lainnya".

\section{Pengertian Akuntansi}


Danang (2013: 18), “Akuntansi adalah proses pencatatan, penggolongan, peringkasan,, pelaporan, dan penganalisisan data keuangan suatu organisasi”.

\section{Pengertian Visual Studio}

Microsoft Visual Studio by merupakan sebuah perangkat lunak lengkap (suite) yang dapat digunakan untuk melakukan pengembangan aplikasi, baik itu aplikasi bisnis, aplikasi personal, ataupun komponen aplikasinya, dalam bentuk aplikasi console, aplikasi Windows, ataupun aplikasi Web. (Wikipedia bahasa Indonesia, ensiklopedia).

\section{Pengertian Crystal Report}

(Irnawan dan Yesni, 2011). Crystal Report juga merupakan aplikasi khusus yang digunakan untuk merancang berbagai macam jenis laporan. Pertama kali Crystal Report diciptakan oleh Crystal Services Inc sebagai alat bantu untuk mereka untuk menciptakan Report secara mudah dan cepat. Hal ini dikarenakan kesulitan yang dialami Crystal Services Inc untuk menemukan seorang developer yang khusus menangani pembuatan report untuk software aplikasi akuntansi yang Crystal Services Inc kembangkan.

\section{METODE PENELITIAN Jenis dan Sumber Data}

Jenis data yang dilakukan oleh peneliti adalah data sekunder dimana data tersebut didapatkan dari hasil pengambilan dokumen. Sedangkan untuk sumber data sendiri peneliti khususkan tempat dimana peneliti jadikan objek penelitian yaitu pada pada PT. Halmahera Karya Timur Persada.

\section{Metode Analisis Sistem}

Pendekatan analisis dan pengembangan sistem yang digunakan dalam penilitian ini adalah Model Driven. Pendekatan Analsis terstruktur adalah salah satu pendekatan formal pertama untuk analisis sistem informasi dan Perancangan Sistem, yaitu suatu proses mengimplementasikan urutan langkah untuk menyelesaikan suatu masalah dalam bentuk program. Pendekatan terstruktur dilengkapi dengan alat-alat (tools) dan teknik-teknik (techniques) yang dibutuhkan dalam pengembangan sistem.

\section{Flowchart sistem yang berjalan}

Sistem yang berjalan merupakan sistem yang lama yang digunakan di PT Halmahera Karya Timur Persada, Berikut merupakan flowchart sistem lama yang ditampilkan pada gambar flowchart dibawah ini:

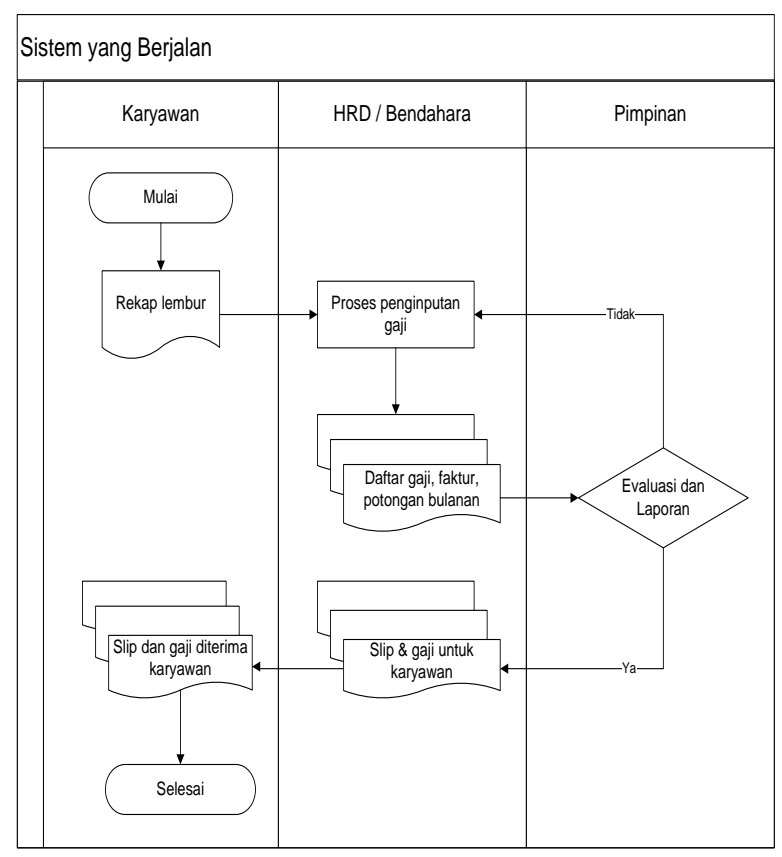

Gambar 1 : Sistem Yang Berjalan

\section{Flowchart sistem yang di usulkan}




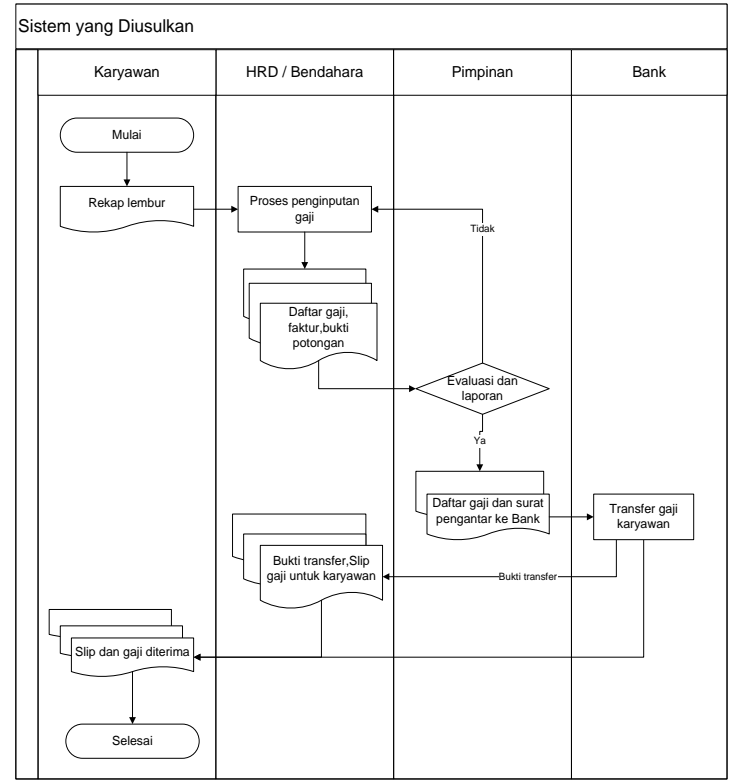

Gambar 2 : Sistem Yang Diusulkan

\section{Perancangan Sistem}

Tahap perancangan sistem mempunyai dua tujuan utama yaitu memenuhi kebutuhan kepada pengguna dan untuk memberikan gambaran yang jelas dan rancangan yang lengkap. Hal-hal yang perlu didalam perancangan sistem meliputi Diagram Konteks, Data Flow Diagram (DFD), Entity Relationship Diagram (ERD), Referential Integrity, dan Rancang tampilan program.

\section{Perancangan Tabel}

\section{Tabel Pengguna}

Tabel pengguna digunakan untuk menyimpan data yang berhubungan dengan Id pengguna:

Tabel 1. Tabel Pengguna

\begin{tabular}{|l|c|c|c|}
\hline Field Name & $\begin{array}{c}\text { Data } \\
\text { Type }\end{array}$ & Size & Primary Key \\
\hline Kd_Pengguna & Text & 12 & Yes \\
Nm_Lengkap & Text & 40 & No \\
User_Name & Text & 25 & No \\
Pass & Text & 12 & No \\
Lvl_Pengguna & Text & 20 & No \\
\hline
\end{tabular}

Tabel Kategori
Tabel kategoti digunakan untuk menyimpan data yang berhubungan dengan pangkat atau jabatan pada pegawai:

Tabel 2. Tabel Kategori

\begin{tabular}{|l|c|c|c|}
\hline FieldName & $\begin{array}{c}\text { Data } \\
\text { Type }\end{array}$ & Size & PrimaryKey \\
\hline Kode & Text & 12 & Yes \\
Kategori & 35 & 50 & No \\
\hline
\end{tabular}

\section{Tabel Pegawai}

Tabel pegawai digunakan untuk menyimpan data yang berhubungan dengan pegawai:

Tabel 3. Tabel Pegawai

\begin{tabular}{|l|c|c|c|}
\hline Field Name & $\begin{array}{c}\text { Data } \\
\text { Type }\end{array}$ & Size & PrimaryKey \\
\hline Kd_Pegawai & Text & 12 & Yes \\
Nm_Pegawai & Text & 40 & No \\
Jenis_Kelamin & Text & 25 & No \\
Agama & Text & 15 & No \\
Pendidikan & Text & 10 & No \\
Kategori & Text & 50 & No \\
Alamat & Text & 75 & No \\
No_Tlp & Text & 15 & No \\
\hline
\end{tabular}

\section{Tabel Pendapatan Pegawai}

Tabel pendapatan pegawai digunakan untuk menyimpan data yang berhubungan dengan pegawai:

Tabel 4. Tabel Pendapatan Pegawai

\begin{tabular}{|l|c|c|c|}
\hline Field Name & $\begin{array}{l}\text { Data } \\
\text { Type }\end{array}$ & Size & PrimaryKey \\
\hline Kd_Pegawai & Text & 12 & No \\
Nm_Pegawai & Text & 40 & No \\
Gaji & Number & - & No \\
UM & Number & - & No \\
TR & Number & - & No \\
Lembur & Number & - & No \\
Jumlah & Number & - & No \\
\hline
\end{tabular}

\section{Tabel Tunjangan}


Tabel tunjangan digunakan untuk menyimpan data yang berhubungan dengan tunjangan pegawai:

Tabel 5. Tabel Tunjangan

\begin{tabular}{|l|c|c|c|}
\hline FieldName & $\begin{array}{l}\text { Data } \\
\text { Type }\end{array}$ & Size & PrimaryKey \\
\hline Kd_Pegawai & Text & 12 & No \\
Nm_Pegawai & Text & 40 & No \\
THR & Number & - & No \\
Seragam & Number & - & No \\
Jamsostek & Number & - & No \\
Tupe & Number & - & No \\
Jumlah & Number & - & No \\
\hline
\end{tabular}

\section{Relation Table}

Hubungan antar tabel (Relation) adalah hubungan antara sebuah tabel dengan beberapa tabel yang lainnya. Hubungan ini menunjukkan relasi antara tabel sehingga membentuk suatu jaringan data.

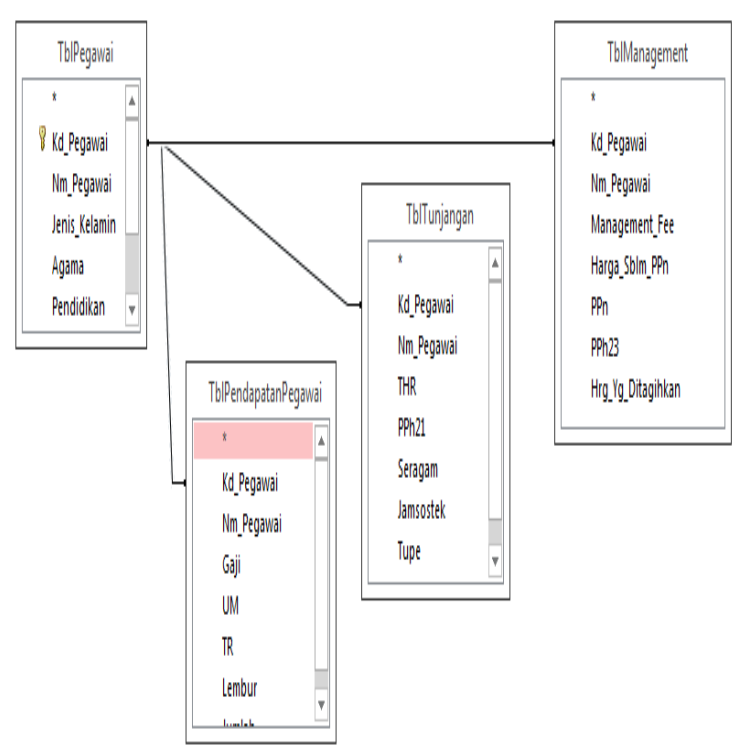

Gambar 3. Relasi Antar Tabel

\section{Diagram Konteks}

Diagram konteks adalah gambaran sistem secara keseluruhan, hanya berisi satu proses yang menggambarkan sistem tersebut terhubung dengan entitas eksternal.

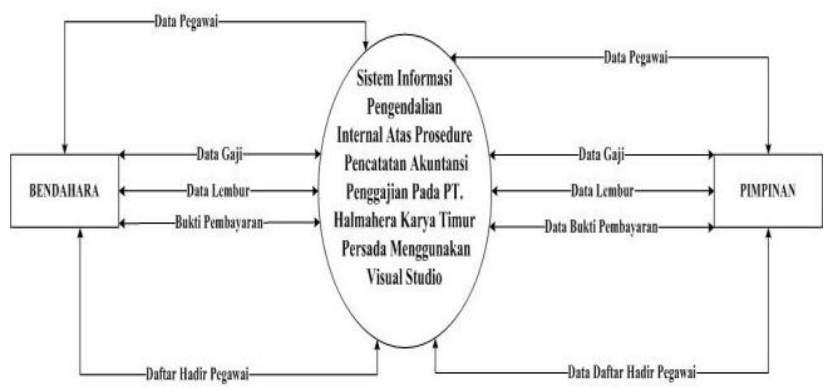

Gambar 4 : Diagram Konteks

\section{Data Flow Diagram (DFD) Level 0 proses 1}

Diagram Konteks adalah gambaran sistem secara keseluruhan, hanya berisi satu proses yang menggambarkan sistem tersebut terhubung dengan entitas eksternal.

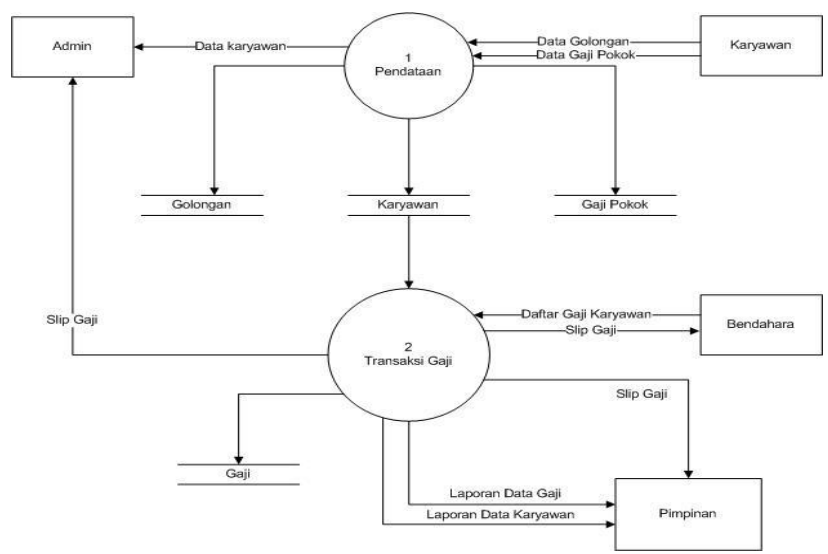

Gambar 5 : DFD Level 0 Proses 1

\section{Diagram Antar Entitas (ERD)}

Entity Relationship Diagram

digunakan untuk menggambarkan hubungan yang terjadi pada setiap entitas :

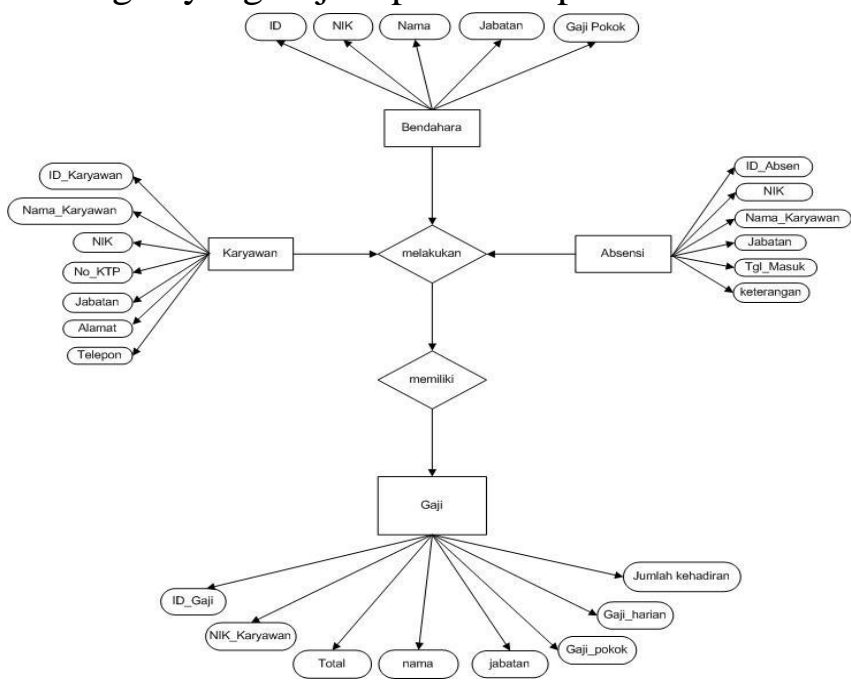

Gambar 6 : Diagram Antar Entitas (ERD) 


\section{Implementasi Sistem}

Tampilan menu utama dari sistem informasi pengndalian internal atas prosedure pencatatan akuntansi penggajian pada PT. Halmahera Karya Timur Persada menggunakan Visual Basic. Menu-menu utama yang di gunakan untuk menampilkan data-data pegawai dan laporan kuangan pada masing-masing data pegawai lainnya.

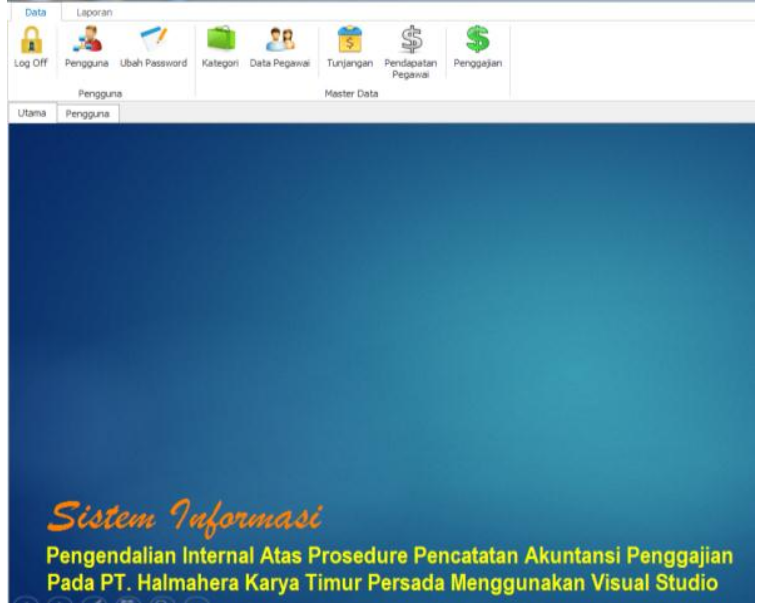

Gambar 7. Tampilan Menu utama

\section{Form Login Administrator}

Orang yang berhak melakukan akses pada halaman ini harus login terlebih dahulu dengan memasukan username dan password.

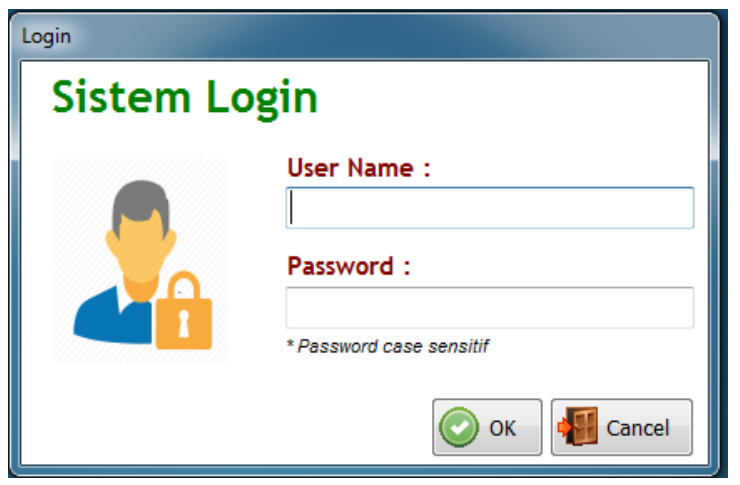

Gambar 8. Form Login Administrator

\section{Form Data Pegawai}

form untuk menginput data pegawai dan di simpan ke database yang nantinya di tampilkan pada tabel dan laporan data pegawai.

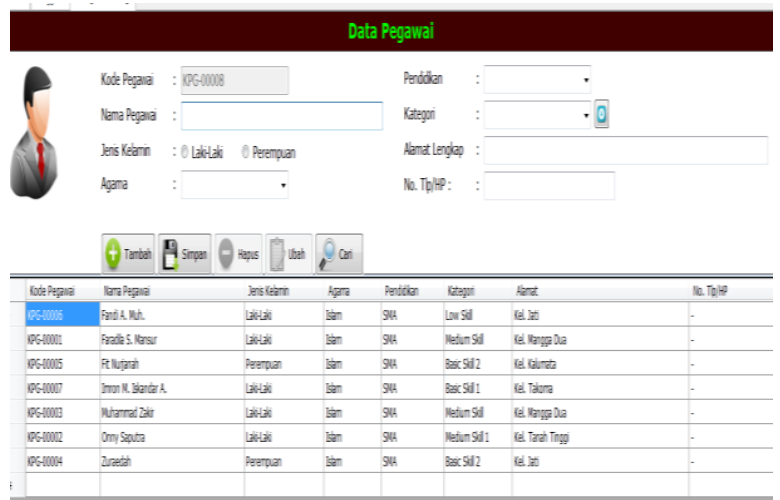

Gambar 9. Form Data pegawai

\section{Form Data Tunjangan}

form untuk menginput data tunjangan pegawai dan di simpan ke database yang nantinya di tampilkan pada tabel dan laporan data tunjangan pegawai.

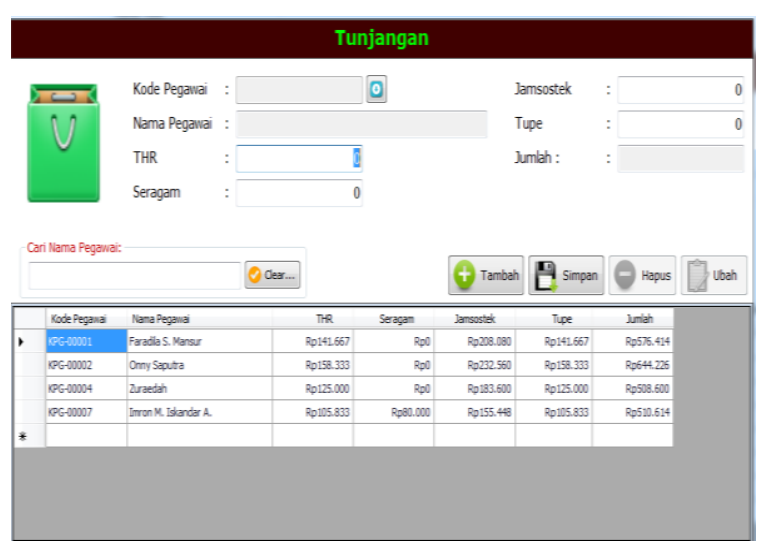

Gambar 10. Form Data Tunjangan

\section{Form Pendapatan Pegawai}

form untuk menginput data pendapatan pegawai dan di simpan ke database yang nantinya di tampilkan pada tabel dan laporan data pendapatan pegawai.

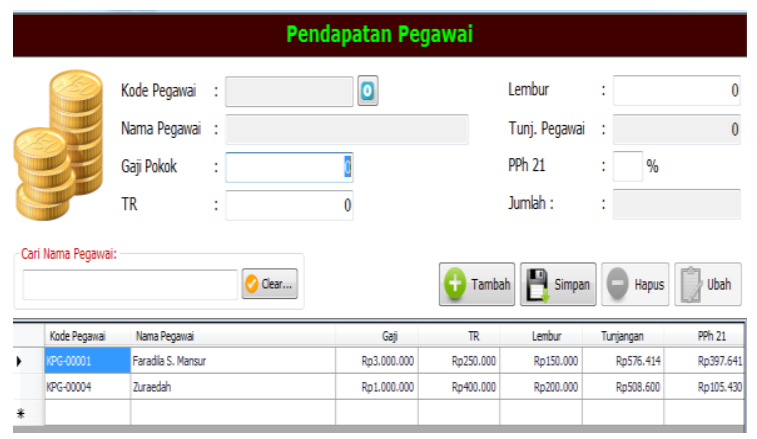

Gambar 11. Form Pendapatan Pegawai 


\section{Form Laporan Data pegawai}

Tampilan form laporan data pegawai seluruh karyawan. Dalam form tersebut dapat dilakukan operasi data dengan melihat data pegawai, cetak data pegawai dan export file lainnya.

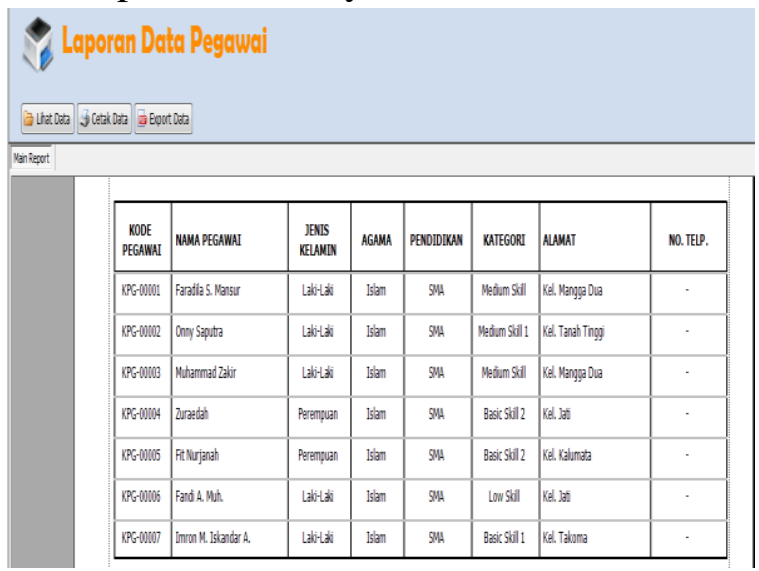

Gambar 12. Form Laporan Data Pegawai

\section{Form Laporan Tunjangan Pegawai}

Tampilan form laporan tunjangan pegawai seluruh karyawan. Operasi data dengan melihat tunjangan pegawai, cetak tunjangan pegawai dan export file lainnya.

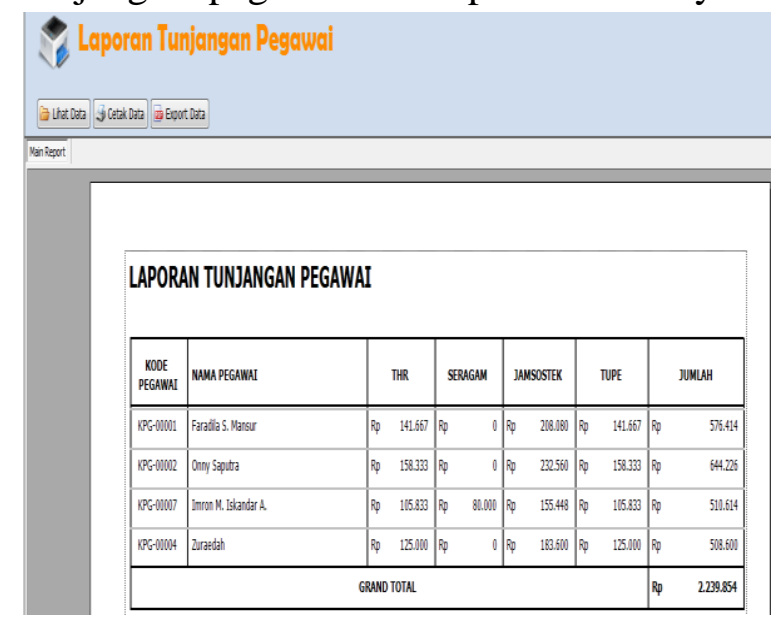

Gambar 13. Laporan Tunjangan Pegawai

\section{Form Laporan Pendapatan Pegawai}

Tampilan form laporan pendapatan pegawai seluruh karyawan. Operasi data dengan melihat pendapatan pegawai, cetak pendapatan pegawai dan export file lainnya.

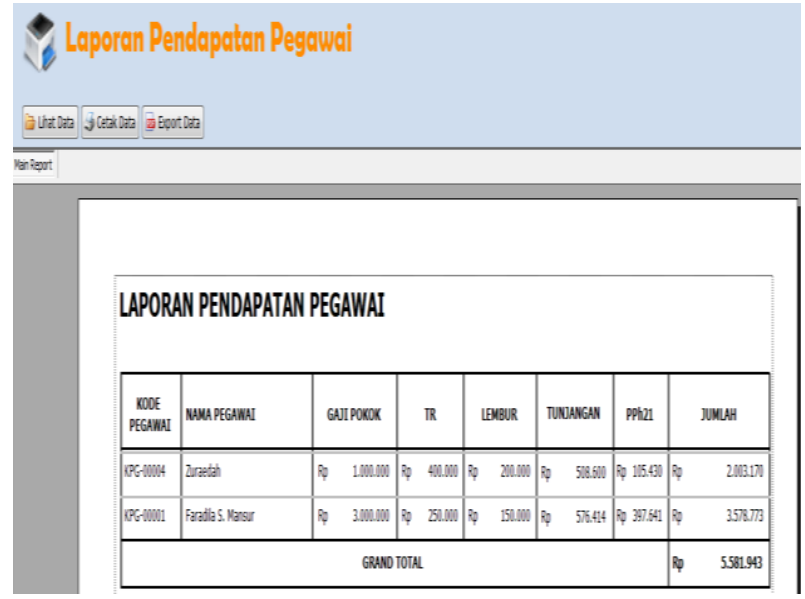

Gambar 14. Laporan Pendapatan Pegawai Form Laporan Penggajian

Tampilan form laporan penggajian seluruh karyawan. Operasi data dengan melihat laporan penggajian pegawai, cetak data dan export file lainnya.

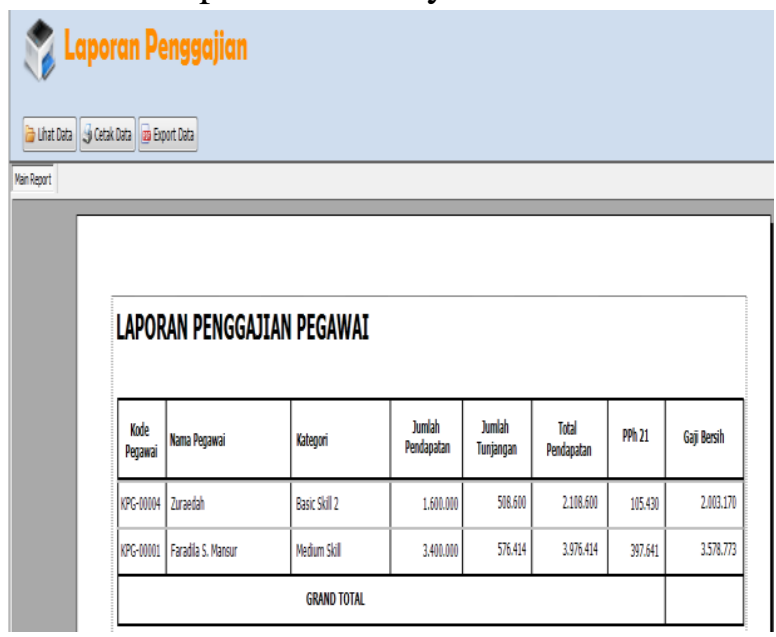

Gambar 15. Laporan Penggajian Pegawai

\section{KESIMPULAN}

Berdasarkan analisis dan perancangan yang dilakukan oleh penulis, maka dapat penulis simpulkan bahwa ada beberapa hal sebagai berikut: 1). Sistem Informasi Pengendalian Internal Atas Prosedure Pencatatan Akuntansi Penggajian Pada PT. Halmahera Karya Timur Persada Menggunakan visual Studio dimaksudkan untuk Memberi kemudahan dalam memasukan data, mengolah data, mencari data dan dalam mencetak data yang perlu dilakukan. 2). Kelebihan dari sistem ini 
adalah Dalam pencarian data lebih cepat, Dapat meminimalkan kesalahan dalam memasukan data, proses perhitungan gaji serta meminimalkan kesalahan yang terjadi.

Berdasarkan kesimpulan di atas, maka diajukan saran sebagai berikut 1). Sistem Informasi Penggajian ini menggunakan visual bsaic yang sederhana, diharapkan dapat di kembangkan lagi menggunakan client server yang lebih sempurna, 2). Sistem informasi yang baru ini hanya mampu dalam pengolahan data pegawai, tunjangan jabatan, pendapatan pegawai dan proses perhitungan gaji. Diharapkan akan ada pengembangan lagi mengenai sistem ini agar lebih banyak menghasilkan informasi yang diinginkan dan lengkap.

\section{DAFTAR PUSTAKA}

Undang-Undang Nomor 13 Tahun 2003 Tentang Ketenagakerjaan

Anonim. 2010. Belajar Pemrograman Visual Basic 2010. Andi: Yogyakarta Irnawan dan Yeni Malau, 2011. Apapun permintaan Crystal Report Jawabnya. PT. Elex Media Komputindo. Jakarta

Mardi. 2011. Tentang Penggajian yang menggunakan Sistem. Penggajian. Ghalia: Indonesia.

Suparjono. 2011. Sistem Akuntansi Penggajian Karyawan Pada BMT Mandiri Sejahtera Kecamatan Ungaran Timur. Tugas Akhir. Universitas Negeri Semarang. Semarang

Sutarman. 2012. Pengantar Teknologi Informasi. PT. Bumi Aksara: Jakarta.

Tata Sutabri. 2012, Konsep Sistem Informasi. Andi: Yogyakarta

Al-Bahra Bin Ladjamudin. 2013. Analisis Dan Desain Sistem Informasi. Graha Ilmu: Yogyakarta.
Danang, Sunyoto. (2013). Metodologi Penelitian Akuntansi. Bandung: PT Refika Aditama Anggota Ikapi.

Hall, James A. (2013). Sistem Infomasi Akuntansi, edisi ke empat terjemahan FitriaSari Dewi, Kawari Deny. Salemba Empat.

Merystika Kabuhung, Sistem Informasi Akuntansi Penerimaan dan Pengeluaran KAS Untuk Perencanaan dan Pengendalian Keuangan Pada Organisasi Nirlaba Keagamaan, JURNAL EMBA: JURNAL RISET EKONOMI, MANAJEMEN, BISNIS DAN AKUNTANSI, Vol 1 No 3 Juni 2013, ISSN 2303-1174

Wikipedia bahasa Indonesia, ensiklopedia, Pengertian Microsoft Visual Studio diakses November 2017 https://id.wikipedia.org/wiki/Microsoft _Visual_Studio 